\title{
Egzotizmin Romantik Dönem Operaları ve Senfonik Süitleri Üzerindeki Etkisi
}

\author{
The Effects of Exotism on Romantic Period Operas and \\ Symphonic Suites
}

\section{Zeynep Simge ACUNAZ EYTEMIZ1 ${ }^{10}$}

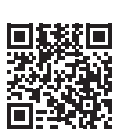

DOI: 10.26650/CONS2021-888442

'Öğretim Görevlisi, Dokuz Eylül Üniversitesi, Devlet Konservatuvarı, Yaylı Çalgılar Anasanat Dalı, İzmir, Türkiye

ORCID: Z.S.A.E. 0000-0003-0478-0924

\author{
Sorumlu yazar/Corresponding author: \\ Zeynep Simge ACUNAZ EYTEMIZ, \\ Dokuz Eylül Üniversitesi, Devlet \\ Konservatuvarı, Yaylı Çalgılar Anasanat Dalı, \\ İzmir, Türkiye \\ E-posta/E-mail: simge.acunaz@deu.edu.tr \\ Başvuru/Submitted: 01.03 .2021 \\ ilk Revizyon/Revision Requested: 10.05.2021 \\ Son Revizyon/Last Revision Requested: \\ 31.05.2021 \\ Kabul/Accepted: 04.06.2021 \\ Online Yayın/Published Online: 00.00 .0000
}

Atıf/Citation: Acunaz Eytemiz, Z.S. (2021). Egzotizmin romantik dönem operaları ve senfonik süitleri üzerindeki etkisi.

Konservatoryum - Conservatorium, 8(1), 103-120. https://doi.org/10.26650/CONS2021-888442

\section{ÖZ}

15. ve 16. yüzyıllarda uzun mesafeli deniz yolculukları sayesinde bilinmeyen diyarlar keşfedildikçe, Avrupa'da egzotik doğuya duyulan merak artmış, insanlar hayal gücünün de etkisiyle, daha renkli ve çekici dünyalara ilgi duymaya başlamışlardır. 19. yüzyılda da sanayileşme sürecinde oluşan zorlu koşullardan yorulan halkın psikolojik bir kaçış ihtiyacıyla bilinmeyen dünyalara duyduğu bu ilginin, egzotizm kavramının Romantik dönemdeki önemli itici güçlerinden biri olduğu düşünülebilir. Önceki dönem eserlerinde sadece yerel bir renk olarak görülen egzotizm, Romantik dönemde kavramlaşmıştır. Bu makalede, Wagner (1813-1883), Verdi (1813-1901), Bizet (1838-1875) ve Rimsky-Korsakov (18441908)'un operaları ve senfonik şiir örnekleri üzerinden egzotizmin Romantik dönemdeki etkisinin açıklanması amaçlanmıştır. Bizet'nin Carmen operasında nota örnekleri üzerinde, egzotik olarak nitelendirilen inatçı bas ve kromatik geçişlerdeki yoğunluk gibi öğeler incelenmiş; yine Bizet'nin Les Pêcheurs de Perles (1863), Wagner'in Parsifal (1812), Verdi'nin Aida (1871) ve RimskyKorsakov'un Scheherazade (1888) adlı eserlerinde ise egzotizmin seçilen konular, karakterler, mekânlar aracılığıyla nasıl yansıtıldığı araştırma yöntemi ile yorumlanmıştır. Wagner'de, seçilen egzotizm öğesinin olumsuz olarak yansıtıldığı, Verdi'de karakter, operanın geçtiği coğrafya ve mekânlar üzerinden belirgin bir egzotizm algısı yaratılığı, Bizet'nin müziğindeki öğeler, mekân, karakter ve kostüm seçimleriyle, Rimsky-Korsakov'un karakter, coğrafya, mekân ve hikâye seçimiyle egzotizmi eserine yansıttığı tespit edilmiştir.

Anahtar Kelimeler: Egzotizm, Oryantalizm, Romantik Dönem

\section{ABSTRACT}

As unknown lands were discovered in the 15th and 16th centuries because long-distance sea voyages became possible, Europe became increasingly interested in the exotic East. People in the West were attracted through the power of their imaginations to more colorful and attractive Eastern worlds. Perhaps, such curiosity about unknown worlds stemmed from a need for psychological escape in people tired of living in the difficult conditions caused by the industrialization processes of the 19th century. This impetus became a significant driving force for the envisioning of exoticism during the Romantic period. Exoticism was viewed merely as local color in musical works of the previous period, but it was conceptualized in the Romantic period. This paper attempts to elucidate the effects of exoticism in the Romantic period 
through the operas and symphonic poems of Wagner (1813-1883), Verdi (1813-1901), Bizet (1838-1875), and Rimsky-Korsakov (1844-1908). It examines elements described as exotic in the note samples in Bizet's Carmen, including the ostinato bass and the intensity of the chromatic transitions. It was further discovered that Bizet's Les Pêcheurs de Perles (1863), Wagner's Parsifal (1812), Verdi's Aida (1871), and Rimsky-Korsakov's Scheherazade (1888) reflect exoticism through selected subjects, characters, and places. It was determined that the exotic element is negatively reflected in Wagner; Verdi creates a distinctive perception of exoticism through characters, geography, and settings; Bizet's music conveys the exotic through the choice of places, characters, and costumes; and Rimsky-Korsakov reflects exoticism to his work through character, geography, setting, and story.

Keywords: Exoticism, Orientalism, Romanticism

\section{EXTENDED ABSTRACT}

As unknown lands were discovered in the 15th and 16th centuries because long-distance sea voyages became possible, Europe became increasingly interested in the exotic East. People in the West were attracted through the power of their imaginations to more colorful and attractive Eastern worlds. In the 19th century, the European states engaged in a global competition to establish empires. Cities proliferated during the industrialization process in Europe, and people who were tired of the difficult conditions of these cities sensed the need for a psychological escape. Perhaps this impetus to escape became the most significant driving force of the concept of exoticism during the Romantic period.

Exoticism was evident in the domain of music in previous periods, but merely as local color. However, it became a concept in the Romantic period that was clearly expressed in works of Romantic-era music by directly using structural features and melodic details of Eastern-influenced folk music. Composers went on journeys beyond Europe to listen to indigenous melodies, analyzed anthropological reports, and were inspired by Asian and African musicians who were brought to Europe's major cities. As an effect of such journeys, the tendency toward folk music (folklorism) and other cultures (exoticism, Orientalism) were pivotal to the development of the composition techniques of the Romantic period (1810-1920). A principal trend of the 19th century, exoticism has been used to express the musical equivalents of distant and foreign orientations in the fields of literature and stage setting.

Exoticism has the power to take people, trapped in a certain routine, to different worlds and can make them dream of the beautiful unknown. Reference to Orientalism is essential along with exoticism because both concepts concern an inclination toward other cultures. One of the most criticized issues about Orientalism is its Western imposition of meaning on the East in which the true East is often not reflected. Exoticism is striking because it is interpreted differently by discrete composers. 
This study examined the operas and symphonic poems of Wagner (1813-1883), Verdi (1813-1901), Bizet (1838-1875) and Rimsky-Korsakov (1844-1908), aiming to explain the effects of exoticism in the Romantic period.

In Rimsky-Korsakov's Scheherazade, exoticism manifests as an unusual breeze wafting from distant lands and extraordinary stories set in mysterious geographies. In Bizet's operas Les Pêcheurs de Perles and Carmen, exotic countries such as Ceylon and Spain and dances, characters, and costumes specific to those countries are repeatedly reinforced, making Bizet one of the foremost composers who contributed to exoticism. Some of the most important parts bestowed with exotic elements were also shared as examples to show exotic reflections in notations. An exotic culture is also evident in Verdi's opera Aida: the night scene in the opera's third act is typical of tropical climates. It is set in Egypt's homes of the pharaohs, Thebes and Memphis; it is one of the most prominent examples of the exotic effect in opera.

Exoticism is depicted using similar elements in Wagner's Parsifal, which showcases Spain and adds a female character in Arabic dress seducing the audience with glamorous dancing. However, it becomes evident at the end of the work that Wagner depicts the negative aspect of exoticism through the female character, Kundry. The third act illuminates Kundry, who embodies exoticism throughout the opera, as someone to regret and from whom to desire deliverance. Thus, the usual depiction of exoticism perception is given a completely different interpretation.

Although exoticism is not a frequently-discussed theme, as can be observed from the similar and divergent interpretations of Romantic-era composers, the idea and its impact on creative output are worth contemplating. Exoticism is an inclination that is too comprehensive to be limited solely to the expression "a longing for distant lands". 


\section{Giriş}

Avrupa toplumunda Sanayi Devrimi sonrasında görülen rasyonelleşme ve şehirleşmeye tepki olarak doğan Romantik hareket, 18. yüzyılın sonundan itibaren sanatçılar üzerinde de etkilerini göstermeye başlamıştır. Besteciler, yazarlar ve ressamlar kişisel ifade ve doğa aşkına yönelmiştir. Bu bağlamda müzik alanındaki hedef, dinleyicinin zekasından çok duygularına hitap etmek olmuştur (Collisson ve diğerleri, 2019, s. 144). Bunun yanında, saray baskısı altında güçlük çeken Klasik dönem bestecilerinin aksine bu dönemde besteciler, duyguları ön plana alarak çoğunlukla özgürce eser yaratma olanağı bulmuşlardır (Acunaz Eytemiz ve Güner Canbey, 2021, s. 97).

Aynı zamanda besteciler, Avrupa'nın ötesindekileri dinleyebilmek için yolculuklara çıkmış, antropolojik raporları incelemiş, Asya ve Afrika müzisyenlerini Avrupa'nın büyük kentlerine getirerek onlardan ilham almışlardır (Griffiths, 2011, s. 201-202). Bu seyahatlerin de etkisiyle, Romantik dönemde (1810-1920) halk müziğine (folklorizm) ve başka kültürlere eğilim (egzotizm, oryantalizm) besteleme tekniklerinin gelişmesinde önemli bir rol oynamıştır (Boran ve Şenürkmez, 2015, s. 176). 19. yüzyılın başlıca yönelimlerinden olan egzotizm, edebiyat alanında ve sahne düzeninde uzak ve yabancı ülkelere ait yönelimlerin müzikteki karşılıklarını ifade etmek için kullanılmıştır (Boran ve Şenürkmez, 2015, s. 177).

Batılılar, bilinenin ötesindeki Doğu'ya büyük ilgi duymuş, onlara yansıtılan çoğunlukla hayal ürünü olan, egzotik diyarlardan etkilenmişlerdir. Bunda, halkın içinde bulunduğu dönemde yaşanılan buhranların ve makineleşmeye giden günlük çalışma hayatlarından kaçma arzularının da payı büyüktür. Egzotizm, belirli bir rutin içinde sıkışan halkı bambaşka dünyalara götürecek ve güzel hayaller kurduracak güce sahiptir. Egzotizmden bahsederken, oryantalizme de değinmek gereklidir çünkü iki kavram da başka kültürlere eğilim hakkındadır. Oryantalizmde en çok eleştirilen meselelerden biri, genellikle gerçek Doğu'nun yansıtılmamasıdır. Batı tarafından idealize edilen bir Doğu'yla karşılaşmak, istenerek veya istenmeyerek Doğu'nun özünden uzaklaşabilmek olasıdır.

Egzotizmde ise bu kavramın farklı bestecilerde farklı yorumlar bulmuş olması dikkat çekicidir. Bu kavramın sadece 'egzotik bir seyahat', 'farklı kültürlere bakış' olarak ele alınmaması yerinde olacaktır. Egzotizmden etkilenen Romantik dönem bestecilerinin eserlerinde gözlemlenebilen bu farklılık, bu kavramın olumlu veya olumsuz olarak ele alınması, sadece eserin hikâyesinde egzotik öğeler olması ama karakterlerde egzotik 
öğelere yer verilmemesi, hikâye çok egzotik değilken egzotizmin karakterler aracılığıyla işlenmesi veya egzotizmin ağırlıklı olarak eserin geçtiği mekân aracıllğıyla pekiştirilmesi gibi farklılıklar söz konusudur.

Romantik dönem bestecileri Richard Wagner (1813-1883), Giuseppe Verdi (1813-1901), Georges Bizet (1838-1875) ve Nikolay Rimsky-Korsakov (1844-1908) adl1 bestecilerin seçilen eserlerinde, yukarıda bahsi geçen farkları ayrıntılı şekilde gözlemlemek mümkündür. Fakat bu ayrıntılı gözlemi yapabilmek için egzotizm eğilimini ayrıntılı şekilde anlamak gereklidir.

\section{Egzotizm}

Hayalî Doğu, bir kavram olarak Batı'nın tam karşıtı olan, sınırları belirsiz bir alanı yani dünyanın her yerini, Batı'nın kendisi ya da kendisinin doğrudan uzantısı saymadığı her şeyi içine almaktadır (Hentch, 1996, s. 9). Doğu, aşırı genellemelerin, fantastik öğelerin birbirine karıştığı egzotik, uzak, belirsiz ve yarı-düşsel, yarı-ilahi bir coğrafyada kurulmuştur (Köse ve Küçük, 2015, s. 122). Egzotizm, içinde oryantalist temaları barındırmas1 sebebiyle, onu anlamak için oryantalizmi de anlamak gereklidir.

Edward Said, Oryantalizm adlı eserinde; Batılıların Doğu'yu ele alırken kendi görüşlerinden ve varsayımlarından hareket ederek Batı'nın çıkarlarına uygun, hayal ürünü bir Doğu manzarası çizdiklerini belirtmektedir. Avrupalı uzmanların, Doğu'nun neye benzediğini kendi perspektiflerinden anlattıkları söylenebilir (Thorpe ve diğerleri, 2015, s. 80). Doğu'ya öteki olarak bakarken, aslında farkında olarak ya da olmadan kendisine bakmakta olan Batılı bilinç, aslında kendisini ifade etmektedir. Batı'nın hayalindeki Doğu tasviri olarak tanımlayabileceğimiz Oryantalizm, sanattan bilime, edebiyattan siyasete kadar Batılı zihin dünyasının her noktasında karşılaşabileceğimiz bir alandır (Köse ve Küçük, 2015, s. 109). Gelişim süreci içinde ele alındığında, oryantalizm, bir yanıyla Doğu'nun Batı tarafından incelenmesi anlamına gelirken, bir yanıyla da Batı'nın kendi bilincine varmasının en önemli aracı olarak gözükmektedir. O nedenle, oryantalizmin sunduğu Doğu imajları, hem Doğu-Batı ilişkilerinin değişmesine, hem de taraflardan herhangi birisinin iç bünyesinde meydana gelen gelişmelere bağlı olarak değişiklikler göstermektedir. Tasavvurda şekillenen Doğu ile gerçek Doğu çelişkilidir. Fakat hayalî Doğu, gerçek doğuya tercih edilmiştir. Doğuya ilişkin tanımlamalarda muhatap hep Batılıdır ve Doğu, Batılı'ya anlatılmaktadır. Oryantalizm, dışsallık üzerine kuruludur ve Doğu'yu, Doğu'nun dışından anlatmaktadır. Doğu, kendinden söz etmeyen; duygularını, 
kişiliğini, kimliğini ifade etmeyen, tarihinin temsilciliğini üstlenmeyen Doğulu adına konuşan Batılılar tarafından temsil edilmektedir. Oryantalizm; Batı'nın ürettiği hayali bir Doğu olmasının yanı sıra, uçuk bir Batı rüyası da değildir. Doğu'nun ve ona ait özelliklerin Batılı gözle yeniden kurulmasıdır ve bu bakış açısı, Doğu dünyasını egzotik ve mistik bir "öteki”, açıklanmaya ve aydınlatılmaya muhtaç bir nesne olarak göstermeye devam etmektedir (Köse ve Küçük, 2015, s. 123-125). Doğu, mitsel egzotizmin diyarı olarak görülmektedir (Thorpe ve diğerleri, 2015, s. 80).

Edebiyat alanında ve sahne düzeninde uzak ve yabancı ülkelere ait yönelimlerin müzikteki karşılıklarını ifade etmek için kullanılan egzotizm kavramı, 19. yüzyılın başlıca yönelimlerindendir (Boran ve Şenürkmez, 2015, s. 177). Robert Louis Stevenson'ın (18501894) Güney Denizi Öyküleri, Henry Wadsworth Longfellow'un (1807-1882) romantize edilmiş Kızılderili dünyasını betimlediği Hiawatha'nın Şarkısı adlı eserleri, egzotizmin edebiyat alanındaki başlıca örneklerindendir. Fransız ressam Paul Gauguin'in 1891 y1lında Fransız Polinezya'sında Tahiti adasına giderek sanatsal ifadenin yeni yollarını keşfetmek istemesi ise egzotizmin resim alanındaki etkisinin Romantik dönemdeki önemini vurgulamaktadır (Collisson ve diğerleri, 2019, s. 199).

Önceki dönem eserlerinde sadece yerel bir renk olarak gördüğ̈̈müz bu kavram, Romantik, Post Romantik ve Modern dönem müziğinde, etkilenilen halk müziğinin yapısal özellikleri ve melodik ayrıntılarının doğrudan kullanılmasıyla eserlerde net bir şekilde ifade edilmiştir. Barok dönem bestecisi Lully'nin Kibarlık Budalası adlı operasının Türk sahnesinde monoton şekilde tekrarlanan "Allah" kelimesinin yarattığı etki ile Romantik dönem bestecisi Verdi'nin Aida adlı operasındaki etki farklıdır (Boran ve Şenürkmez, 2015, s. 177). İlk örnekte, daha önce de ifade edildiği gibi daha geçici, hayali bir etki vardır. Fakat diğerinde eserin tümüne etki eden fikirsel ve kavramsal bir aktarım söz konusudur.

Bu örneklere dayanarak, egzotizmle ilgili farklı fikirlerden bahsetmek gereklidir. Örneğin, Jonathan Bellman'a göre müzikal egzotizm, etnomüzikolojik gerçeğe eşdeğer değildir. Yabancı kültürleri ciddi bir şekilde incelemekle de ilgilenmemektedir. Ona göre müzikal egzotizm; drama, etki ve çağrışımla ilgilidir. Dinleyiciye ilgisini çeken, lezzetli bir şeyler sunulmaktadır. Bunun yanı sıra pek çok akademisyen de egzotik müzikal öğelerin, Batı dışı müzik geleneklerinin gerçek üslup özellikleriyle çok az ilişkiye sahip olduğunu düşünmektedir (Bellman, 1997, s. xii-xiii). "Sanatçıların geleneksel merceğinden kendi- 
leri için ideal bir Doğu uyduranlar bir şekilde hayal kırıklığına uğradılar" ifadesi ise egzotizmle ilgili bir diğer farklı düşüncedir (Fauser, 2005, s. 114).

\section{Richard Wagner (1813-1883): Parsifal (1812)}

Wolfram von Eschenbach'ın ölümsüzleştirdiği büyük Hristiyan efsanesi Parsifal ile 1845 y1lında ilgilenmeye başlayan Wagner, 1858 yılında metni planlayarak, 1877'de bitirebilmiştir. 1879 yılında bestelemeye başlamış, 1882 yılında ise orkestrasyonunu tamamlamıştır (Yener, 1992, s. 167).

Parsifal operasinda Kuzey efsanelerinden ilham almaya devam eden Wagner, konu olarak Kral Arthur efsanesinin bir kesidini seçmiştir. İngiltere'nin yeniden refaha kavuşması için, artık yaşlı ve hasta olan Kral Arthur'un iyileşmesi gerekmektedir. Bunun için İsa'nın son akşam yemeğinde şarap içtiği Kutsal Kâse arayışına çıkan Şövalye Parsifal konu olarak işlenmiştir. Parsifal, Katolik dinine ait öğeler barındırması sebebiyle, Wagner'in diğer operalarından farklıdır (Boran ve Şenürkmez, 2015, s. 227).

Parsifal, din ve kurtuluş hakkındadır. Ancak din ve kurtuluş kendi başlarına anlamlı bir şekilde var olamayacağı için, paganizm ve lanetle de ilgilidir. 1880'de Parsifal üzerinde çalışırken, Religion und Kunst adlı kitabında sanatın görevinin din içinde yatan ve zamanla yavan bir hal alan efsanevi sembolleri yeniden kendine mal etmek olduğunu savunan Wagner, bu sembolleri ideal bir biçimde yeniden sunmayı hedeflemiştir (Dahlhaus, 1971, s. 141). Bununla birlikte, Parsifal'in mitlerinin yalnızca Hristiyan terimleriyle ya da bu nedenle Wagner'in o sırada ilgilendiği Budizm bağlamında açıklanamayacağ açıktır (Emslie, 1991, s. 111). Operanın müzik ve librettodaki temel zıtlığı, çiçek bakirelerinden oluşan büyülü bir bahçenin yetiştiricisi olan kötü niyetli Klingsor ile topraklarını el değmemiş bir vahşi doğa olarak bırakan ve Kutsal Kitap'ın sağladığı şeylere bağlı olan erdemli Kâse topluluğu arasındadır (Burnett, 2014, s. 1).

Operanın daha çok bilinen kısımlarından biri, ikinci perdenin ikinci sahnesindeki Çiçek Bakireleri ile Karşılaşma 'dır. Bu sahnede, çiçek kılığındaki kızlar delikanlıyı kandırmaya çalışmaktadır. Fakat bu da bir aldatmacadır; bu egzotik atmosfer, büyücü Klingsor tarafından yaratılmıştır (Yener, 1992, s. 169). Burada, egzotizmin aldatıcı tarafı da göz ardı edilmemelidir. Temelinde, insanların gerçeklerden uzaklaşma ihtiyacı olan egzotizmin, operanın bu sahnesinde büyücü tarafından yaratılan bu 'gerçek olmayan' ortamda kendisini göstermesi anlamlıdır. Opera, İspanya'da geçmesi sebebiyle 'egzotik' olarak 
nitelendirilse de, bahsi geçen sahnedeki ayrıntı da, egzotizmin kelime anlamına yakınlığ sebebiyle ayrıca dikkate alınmalıdır.

Operanın bir diğer önemli egzotik unsuru ise, Kundry karakteridir. Orijinal Parsifal efsanesinde, Kundry, grotesk yüz özelliklerine sahip çirkin, itici bir kadındır. Ancak Wagner, Kundry tasvirinde son derece önemli bir değişiklik yapmış, onu güzel, çekici ve baştan çıkarıcı olarak tanımlamıştır. Parsifal'i elde etmeye çalıştı̆̆ında Arap kıyafetleri giyen, oryantal tavırlar içinde olan Kundry, bu operada oldukça egzotik ve erotik bir kadına dönüştürülmüştür (Babyak, 2014, s. 181-182).

Ayrıca Kundry, Kâse topluluğunun sosyal dokusuna sarsıcı bir unsur enjekte eden yıkıcı bir güç olarak tasvir edilmiştir. Müziği onu, sıkı sıkıya bağlı, şövalyeler topluluğunu tehdit eden egzotik bir davetsiz misafir olarak kodlamıştır. Kısaca, bir sanat eserinde aralıklı olarak tekrarlanan temel motif olarak tanımlayabileceğimiz Leitmotif, müzikal egzotizmin standart bir işareti olan artırılmış saniyelerle süslenmiştir. Wagner, Kundry'a kromatizmle damlayan bir ana motif vermiş, kendisinden her bahsedilişinde leitmotifini belirterek, kendisiyle egzotik sebep arasında güçlü bir ilişki kurmuştur. Dinleyici böylece, Kundry'yi egzotik olarak algılamaya şartlandırılmıştır (Babyak, 2014, s. 183-185). Bu, Wagner'in operalarında sıklıkla gözlemlediğimiz bir durumdur. Bilindiği üzere Wagner, operaları aracılığıyla dinleyicide büyük etkiler bırakabilen ve onları ikna edebilen bir bestecidir.

İkinci perdede Kundry, Klingsor'un büyülü kalesinde yer almaktadır. Bu kaledeki herkes (Klingsor, Kundry ve çiçek bakireleri) egzotiktir; böylece, Kundry bu dünyaya karışmıştır ve yabancı olarak görülmemektedir. Bu sebeple, onu ilk perdede egzotik bir yabancı olarak işaretleyen leitmotifi, ikinci perdede pek duyulmamaktadır. Fakat, Parsifal' in Kundry'yi uzaklaştırarak Amfortas ve Kâse topluluğu için haykırdığı anda leitmotifi orkestrada iki kez duyulmaktadır. Kundry'nin ait olmadığı bir dünya, onu bir kez daha egzotik bir yabancı olarak işaret etmektedir. Böylelikle, Parsifal Amfortas'tan ve kadehten bahsettiğinde, Kundry'nin egzotik leitmotifi birkaç kez duyulmaktadır. Kundry'nin leitmotifi Parsifal' in Amfortas'1 kurtarmak için reddetmesi gereken tehlikeli egzotizmi ima etmektedir. Aynı sahnenin ilerleyen kısımlarında Parsifal, "Bakışlarım artık Kutsal Kâse'ye sabitlendi” derken, Hıristiyanlığa olan sadakatini göstermektedir. Kutsal Kâse'nin burada Hıristiyanlığı sembolize ettiği unutulmamalıdır. Bu tavır, Parsifal'in, Kundry'nin baştan çıkarıcı, egzotik cazibesine direnme kararlılığını ifade etmektedir (Babyak, 2014, s. 185). 
Üçüncü perdede Kundry'nin egzotik leitmotifi yoktur. Bunun sebebi, Kundry'nin egzotik kimliğini Hıristiyan kimliği ile değiştirerek, kendisini kâse topluluğu içinde asimile etmesidir. Günahlarını kabul etmiş, baştan çıkaran, egzotik bir kadın olmaktan çıkmış, pişman ve ölümünü alçakgönüllülükle kabul eden bir kadın haline gelmiştir (Babyak, 2014, s. 186). Burada dikkat çeken şey, Wagner'in metafiziği olumlu, egzotizmi olumsuz şekilde tasvir etmesidir. Egzotizm, diğer birçok bestecinin eserlerinde farklı bir renk, uzak diyarlardan gelen bir esinti, bir değişiklik olarak kendini göstermekteyken, Wagner'in Parsifal adlı operasında, Kundry adlı karakter, önce bize diğer egzotik karakterler gibi tanıtılsa da eserin ilerleyen sahnelerinde alışılagelmişin dışında, kurtulmak istenilen bir kadın olarak yorumlandığı söylenilebilir. Wagner'in egzotizme dair bu değişik yorumu oldukça farklı, incelikli ve dikkat çekicidir.

\section{Giuseppe Verdi (1813-1901): Aida (1871)}

Egzotik bir opera olarak nitelendirilen Aida'nın konusu Mısır' ın Firavunlar döneminde, Teb'de ve Memphis'te geçmektedir. Firavun Ramphis'in kızı Amneris'in Etiyopyalı kölesi olan Aida, Mısır ordusunu Etiyopya'ya karşı komuta etmek üzere gönderilecek olan Ramades'e aşıktır. Amneris de Radames'e aşıktır fakat Radames' in Aida'ya olan ilgisinin farkındadır. Fakat Radames'in Etiyopya ile savaşacak olması Aida için oldukça üzücüdür çünkü Aida'nın babası Amanasro da Etiyopya ordusunu komuta edecektir. Aida, aşkı, babası ve vatanı arasında kalmıştır (Yazar, 2006, s. 67).

İkinci perdede Radames savaştan zaferle dönmüştür ve Firavun ona başarılarının ödülü olarak Amneris'le evleneceğini söylemiştir. Operanın üçüncü perdesinde, operadaki egzotik etkiyi güçlendiren tropik iklimlere has bir gece görülmektedir: Ay 1şı̆̆ı palmiye yaprakları arasından süzülerek Nil sularında titrek yankılar yapmaktadır. Aida gizli aşkı Radames'i beklemekteyken, babasına yakalanmıştır ve babası ondan yaptığ kaçış planına katılmasını istemektedir. Aida razı olmamıştı fakat Radames Aida ile kaçma planları yaparken askerlerinin yerini açık etmiş ve onları gizlice dinleyen Aida'nın babasını görünce şerefini kaybettiğini anlamıştır. Bu esnada Amneris ve başrahip, Radames'i düşmanları ile birlikte görünce muhafiz askerlerini çağırmışlardır. Amonasro ve Aida, Radames'i onlarla birlikte kaçmaya ikna etmeye çalısssalar da Radames bunu kabul etmemiş ve Firavun'un muhafizlarına kendini teslim etmiştir. Aida ve babası Amonasro kaçmak durumunda kalmıştır (Yener, 1992, s. 224).

Dördüncü perdenin ilk sahnesinde Amonasro öldürülmüş, Radames ise Amneris'le evlenirse kurtulabilecek olmasına karşın bunu reddetmiş ve vatan hainliği sebebiyle diri diri 
gömülmeye razı olmuştur. İkinci sahnede ise, mezarda ölmeyi bekleyen Radames karş1sinda Aida'y1 görünce bunun bir hayal olduğunu düşünse de aslında Aida onunla ölmek için mezara saklanmıştır. Radames genç sevgilisinin hayatını mahvettiğine üzülmekteyken Aida huzurla yeryüzüne veda etmeye hazırdır. Amneris ise Radames'in mezarı başında hıçkırarak veda etmekteyken opera sonlanır (Yener, 1992, s. 225).

Librettosunun ve sahne tasarımının görkemi, marşlarla desteklenmiş tarihsel ve siyasal göndermeleri ile Aida operası, Misır tanrılarından Nil Nehri kıyısına kadar Misır'a dair belgesel bir gösteri olarak, görkemli ve egzotik unsurlarla kurgulanmıştır (Yazar, 2006, s. 71).

Süveyş Kanalı'nın açılması, Doğu'nun uzaklığını ortadan kaldırmasının yanı sıra, onun üzerinde hem coğrafi hem de kültürel bir egemenlik kurma düşüncesini de beraberinde getirmiştir. Aida operası, Mısır'da kültürel bir hareketliliği ortaya koyması açısından da önemli bir yere sahiptir (Yazar, 2006, s. 72).

\section{Georges Bizet (1838-1875): Les Pêcheurs de Perles (1863), Carmen (1875)}

Bizet, egzotizmi kendi hayal gücüne güvenerek canlı ve çekici bir şekilde tasvir etmeye yönelmiştir ve yarattığı bu farklı tarz onu egzotizm konusunda önemli bir isim haline getirmiştir (Babyak 2014, s. 86-87). Bizet'nin operalarının çoğu egzotik yerlerde geçmektedir: Seylan'da Les Pêcheurs de Perles (1863), Orta Doğu'da Djamileh (1873), Carmen İspanya'da geçmektedir ve ana karakteri bir çingenedir. Bizet'in operalarındaki egzotizmin kaynağı sadece içinde geçtikleri egzotik ortamlarla sınırlandırılmamalıdır. Müziği ve kullandığı diğer egzotik öğelerle, eserlerinde kuvvetli bir doğu içgüdüsünü gözlemleyebildiğimiz Bizet, dönemin egzotizme en çok katkı sağlayan bestecilerindendir (Babyak, 2014, s. 25).

Bizet'in, operatik egzotizmdeki ilk girişimlerinden biri olan Les Pêcheurs de Perles, yasak aşk ve aşırı cinselliğin çarpıcı bir hikâyesidir. Ölüm acısı üzerine iffetli kalmaya söz veren bakire bir rahibe olan Leila, yakışıklı Nadir' in ayartmalarına boyun eğerek yeminine itaatsizlik etmiştir ve Nourabad adlı rahip tarafindan yakalanarak, günahkâr davranışları yüzünden yetkililere teslim edilmişlerdir. Kabile şefi Zurga, önce her ikisini de ölüme mahkûm etse de sonra onları affetmiştir. Bunun sebebi, kendisinin de Leila 'ya âşık olması ve onun ölmesini istememesidir. Bu hikâyede, 19. yüzyıl Fransız izleyicisi- 
nin sevebileceği yasak aşk, yasak cinsellik, egzotik bir ortamda, egzotik bir müzikle sunulmuştur (Babyak, 2014, s. 25).

Les Pêcheurs de Perles gibi, Bizet'nin Carmen adlı operası da egzotik öğeleri serbestçe kullanmıştır. Fakat bu operada özel olarak İspanyol ritimleri ve ezgileri kullanılmıştır (Boran ve Şenürkmez, 2015, s. 213). İspanya ile güçlü bağlara sahip bir dans türü olan 'Habanera', operanın İspanyol egzotizminin en iyi örneği olarak kabul edilmektedir.

Nietzsche, Carmen'deki "Habanera" ve "Seguidilla" danslarından ve şehvetli egzotizmden övgüyle bahsetmiştir. Bizet'nin egzotik çingene dünyası tasvirini Almanya'nın hastalıklarından egzotik bir kaçış olarak nitelendirmiş ve baştan çıkarıcı bir pagan ülkesinin temsil edildiğini düşündüğünü belirtmiştir (Babyak, 2014, s. 165-166). 


\section{Nọ 5. Habanera.*)}
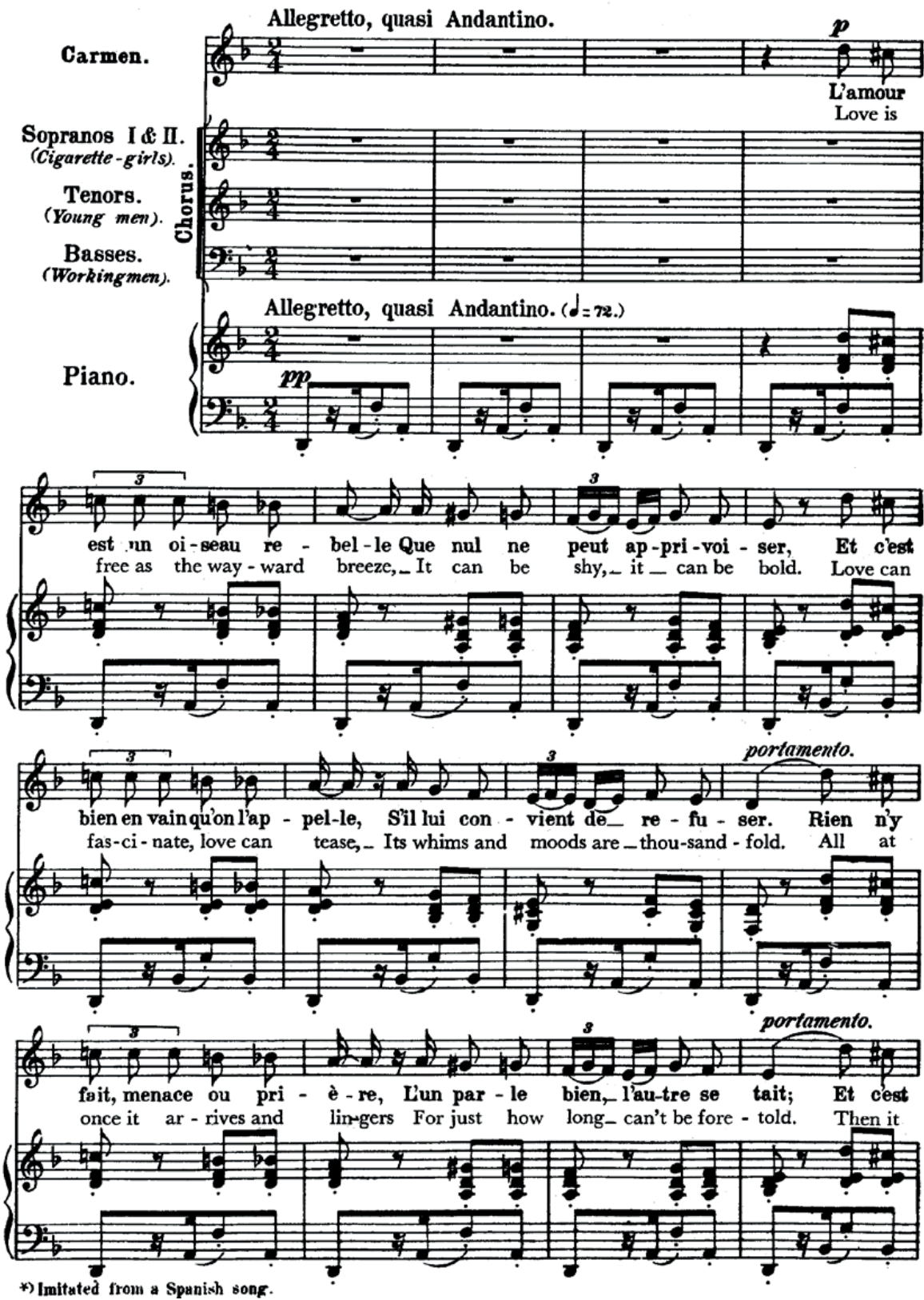

Örnek 1. Carmen, ö.1-16 (Bizet, 1875/1905, s. 84). 
Yukarıdaki Habanera örneğinde, ostinato bir bas ritmin yoğun bir şekilde kullanıldığ1, bir oktav boyunca uzanan bir dizi kromatik iniş gözlemlenmektedir (Örnek 1). Çoğu egzotik eserde karşımıza çıkan bu tanıdık özellikler, eserdeki egzotizm etkisini net bir şekilde göstermektedir. Carmen' in kışkırtıcı kromatik geçişleriyle eşleştirilen inatçı bas, egzotik bir ses dünyası yaratmaktadır. Fakat bu ses dünyası sadece egzotik değil, aynı zamanda erotiktir. David'in ve Berlioz'un, kıvrımlı melodik figürlerle süslediği, dans eden çekici kızların kışkırtıcı bir tasvirini sunduğu Almée danslarında da gözlemleyebildiğimiz gibi, erotizm birçok egzotik eserin merkezi bir bileşenidir. Bu operada erotizm daha da belirgindir; Carmen baştan çıkarıcı şarkısını alaylı bir ifadeyle söylerken, baştan çıkarıcı bir şekilde dans etmektedir (McClary, 1997, s. 76).

Habanera ve Seguidilla Carmen'in İspanyol tarafını sergilerken, çingene kimliğini de aşağıda verilen örnekte gözlemlemek mümkündür (Örnek 2). Çingene Şarkısı başlıklı bu aryada Carmen ve birkaç çingene kadın şarkı söylemekte ve gitar, tef gibi egzotik enstrümanlar çalmaktadırlar (Babyak, 2014, s. 34-35).

\section{Act II.}

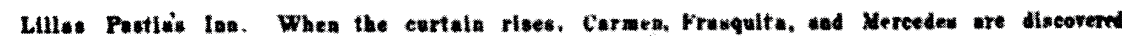

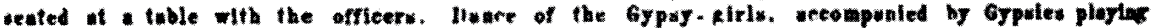
the gultur and tabourine.

No 12. Gypsy Song.
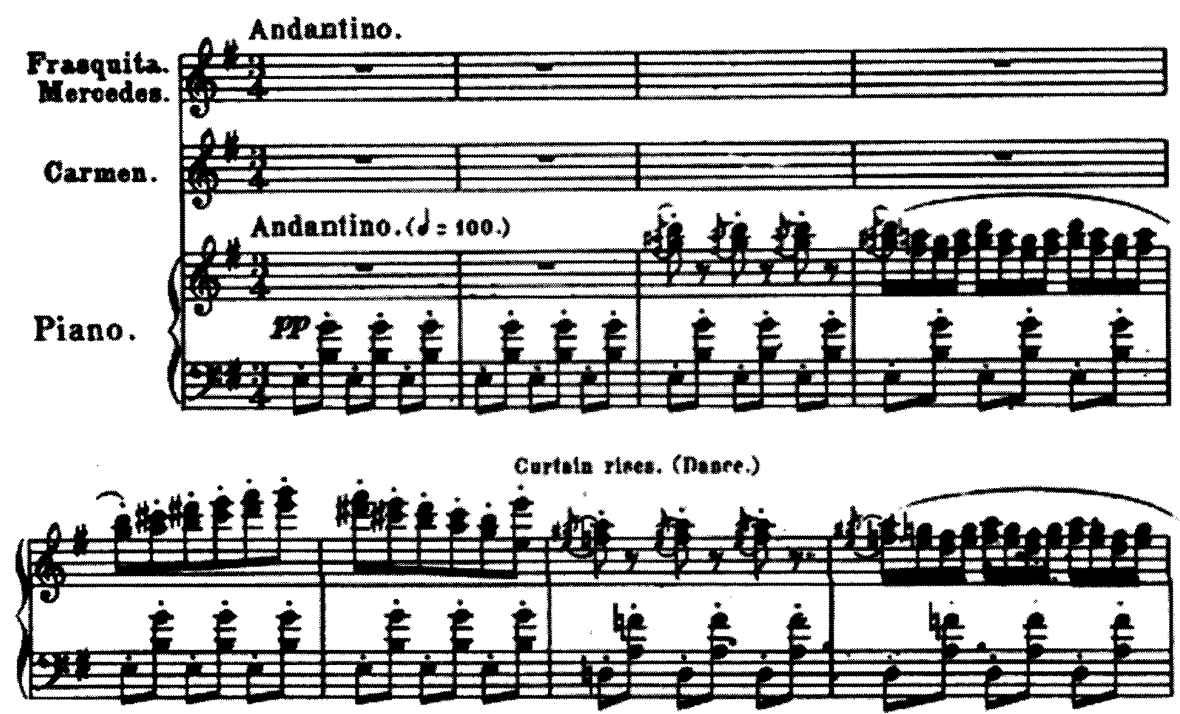

Örnek 2. Carmen, ö.1-8 (Bizet, 1875/1905, s. 185). 
Yukarıda bahsedildiği üzere, Carmen'de bulunan özelliklerin çoğu, David ve Berlioz'da incelediğimiz egzotik öğelerle benzeşmektedir ve Bizet'nin Carmen'deki müzik dilinde de gerçek İspanyol etkisinden çok, Fransız oryantalist etkileri gözlemlemek mümkündür. Bu sebeple, Bizet'nin Fransız egzotizm öğelerinden yararlandığı söylenilebilir (Babyak, 2014, s. 37-38).

Operadaki diğer egzotik öğeleri gözlemleyebilmek için operadan da ayrıntılı şekilde bahsetmek gereklidir: Açılış sahnesi 1830'larda İspanya'nın Sevilla kentinde geçen operada Carmen, herkesin dikkatini çeken bir kadındır fakat asker Don José onu fark etmemiş gibi yapsa da hızlı düşünen Carmen, José 'yi baştan çıkararak kaçmış, bu da José'nin görevi ihlal ettiği için tutuklanmasıyla sonuçlanmıştır. Bir ay sonra, Carmen ve arkadaşları bir tavernada askerleri eğlendirmekteyken ünlü bir boğa güreşçisi olan Escamillo gelmiş ve José'nin hapisten çıkmasını beklediği için onu reddeden Carmen ile flört etmiştir. Fakat José geldiğinde Carmen, onu erotik bir dansla ödüllendirmiş ve gece kışlaya dönmeye hazırlanırken, onu gerçekten severse onunla kaçacağını söyleyerek alay etmiştir. O anda, Jose'nin teğmeni, Carmen'i tutuklamak için geri dönmüştür. Carmen yüzünden Jose ile teğmen arasında kavga çıkmış ve Carmen'in kaçakçı çetesinin araya girmesi üzerine kavga sonlanmıştır. Bu olayın sonunda José, üst düzey bir subaya saldırdığı için, Carmen ve kaçakçılarla birlikte dağlara kaçmak zorunda kalmıştır. Dağlarda José 'den sıkılan Carmen, ona annesinin yanına gitmesini tavsiye etmiştir. Escamillo gelmiş ve ayrılmadan önce herkesi bir sonraki boğa güreşine davet etmiştir. Carmen, Escamillo'nun kolunda olmasına rağmen, arenanın dışında José'ye koşmuş ve José, Carmen'e onunla birlikte uzaklaşması için yalvarmıştır. Ancak Carmen özgür doğduğunu ve özgür öleceğini söyleyerek onu reddetmiştir. Arenadaki kalabalık Escamillo'yu zafer için alkışlarken, José kıskanç bir öfke içinde Carmen'i bıçaklayarak öldürmüştür (Yener, 1992, s. 286-289).

Bizet, Carmen'de, ahlaki değerleri on dokuzuncu yüzyıl seyircisini şok eden bir baş karakterle sunarak çingene kültürünü romantikleştirmiştir ve metni Fransız yazar Prosper Mérimée'ya ait olan bu opera, birçok egzotik eserde olduğu gibi, dinleyicinin uzak diyarlara dair hayallerini pekiştirmiştir (Machlis ve Forney, 2003, s. 452).

\section{Nikolay Rimsky-Korsakov (1844-1908): Scheherazade (1888)}

Rimsky-Korsakov, Scheherazade'ı bestelerken The Thousand and One Nights (The Arabian Nights) olarak bilinen büyük ölçüde Orta Doğu ve Hint masallarının koleksiyonun- 
dan ilham almıştır. Temalarını 1800'lü yıllarda Avrupa'da yaygın olarak tanınan Denizci Sinbad ve Oduncu Ali Baba gibi karakterleri çağrıştıran hikayelerden almıştır. Renkli ve çok çeşitli bir ruh hali olan eser, Scheherazade'ın kendisini temsil eden yinelenen bir keman solosuna ve padişaha karşılık gelen derin, ağır bir temaya sahiptir.

Rimsky-Korsakov, eseri 1888'de tamamlamış ve o yılın 3 Kasım'ında Saint Petersburg'da, prömiyerini gerçekleştirmiştir (Schwarm, 2016). Çerçeve hikâye olarak bilinen, hikâye içinde hikâyeler şeklinde sunulan eserde, Şehrazat'1n Sultan Şehriyar'a karş1 stratejik oyunları ve bin bir gece boyunca süren hikâyesi anlatılmaktadır (Hopa, 2019, s. 105). Çerçeve hikâye tekniği ile anlatıcıya sunulan masallarda ana karakter Şehrazat, güçlü bir sultan olan Şehriyar'a karşı stratejik bir oyun sergilemekte ve bin bir gece boyunca sürecek olan masallar anlatmaktadır. Rimsky-Korsakov'un yazdığı birinci bölümün giriş kısmında kısaca işlenen konu, Şehrazat masalıdır (Girgin, 2015, s. 110). Binbir Gece Masalları'nda kahramanların adlarında, olayların geçtiği coğrafyada, masalların konularında, özellikle Arap ülkeleri ile İran ve Mısır adlarının ön plana çıktığı görülmektedir (Nazlı, 2011, s. 16). Ayrıca, eserde uzak diyarlardan gelen farklı bir esinti, alışılmıŞın dışında hikayeler vardır. Bu sebeple ‘Binbir Gece Masalları’ dönemin oryantalist ve egzotik eserleri arasında yer almaktadır.

Süit, başlangıçta başlıksız olarak tasarlanmış ancak daha sonra Rimsky-Korsakov'un eski öğrencisi Anatoly Lyadov tarafından isimler verilerek dört bölüm halinde yapılandırılmıştır. İlk bölüm olan The Sea and Sinbad's Ship (Deniz ve Sinbad'ın Gemisi), padişahın rüzgâr ve iplerdeki derin, müthiş sesi ile başlar ve padişah, en yeni eşinin kendisini eğlendirmesini ister; hafif, lirik bir solo keman melodisiyle temsil edilen Şehrazat, hikayesini geliştirmeye başlamaktadır. İkinci bölüm, The Kalandar Prince (Prens Kalender'in Hikayesi), Şehrazat'ın artık tanıdık olan keman solosuyla başlayarak marş benzeri hareketli pasajlara dönüşerek aralıklı olarak sultanın temasının önerileriyle iç içe geçmektedir. Üçüncü bölüm The Young Prince and The Young Princess (Genç Prens ve Prenses), aşk hikayesi anlatan bir valstir. Dördüncü bölümde ise padişah temas1, Festival at Baghdad. The Sea; The Ship Breaks against a Cliff Surmounted by a Bronze Horseman (Bağdat’ta Festival; Deniz, Gemi, Bir Bronz Savaşçının Üstündeki Bir Kayanın Üzerinde Parçalara Gidiyor) adlı heyecanlı finali tanıtmakta ve önceki hareketlerden birçok temayı yeniden ziyaret ederek yeniden canlandırmaktadır (Schwarm, 2016). 
Eserdeki bölümlerin isimleri The Thousand and One Nights'1n orijinal öykülerinden türetilse de Rimsky-Korsakov her zaman müziğin belirli bir masalın veya koleksiyonun herhangi bir parçasının tam bir tasviri olarak tasarlanmadığı konusunda ısrar etmiş̧tir. Eserde Şehrazat' 1 temsil eden nazik ve zarif tema, solo keman tarafindan duyurulurken, sert, kaba ve hantal Sultan ise güçlü oktavlarla ifade edilmiştir (Michels ve Vogel, 2013, s. 465).

\section{Sonuç}

Romantik dönemle birlikte kişisel ifade ve doğa aşkına yönelen besteciler, kavram olarak Batı'nın tam karşıtı olan, sınıları belirsiz bir alanı ele alarak, Avrupa'nın ötesinde, mistik diyarlara duydukları ilgiyi eserlerine yansıtmışlardır. Bunun en önemli nedenlerinden birinin Sanayi Devrimi'nin de etkisiyle oluşan zorlu koşullardan psikolojik kaçış ihtiyacı hisseden halk olduğu söylenebilir.

Bu çalışmada egzotizm açıklanarak, Wagner (1813-1883), Verdi (1813-1901), Bizet (18381875) ve Rimsky-Korsakov (1844-1908) adlı bestecilerin egzotizme örnek olan eserleri ele alınmış ve egzotizmin Romantik dönemdeki yeri ve eserlere etkisine değinilmiştir.

Rimsky-Korsakov adlı bestecinin Scheherazade adlı eserinde egzotizm uzak diyarlardan gelen farklı bir esinti, egzotik coğrafyalarda geçen, alışılagelmişin dışındaki hikayeler olarak kendini göstermektedir. Bizet'nin Les Pêcheurs de Perles ve Carmen adlı operalarında yine Seylan, İspanya gibi egzotik ülkeler ve o ülkelere özgü egzotik danslar, karakterler, kostümler ve müzikte kullanılan egzotizm öğeleri defalarca pekiştirilmiştir. Bu sebeple Bizet, egzotizme katkı sağlayan başlıca besteciler arasında yer almaktadır. Verdi'nin Aida operasında ise yine egzotik bir kültür yansıtılmıştır. Mısır'ın Firavunlar döneminde, Teb'de ve Memphis'te geçen operanın üçüncü perdesindeki tropik iklimlere has gece görüntüsü, operadaki egzotizm etkisinin en belirgin örneklerindendir. Bestecilerin egzotizm anlayışları, genel olarak birbirine benzese de Wagner'in egzotizm anlayışındaki farklılık dikkat çekicidir. Egzotizm, Wagner'in Parsifal operasında da İspanya'da geçmesi, Arap kıyafetleri içinde, egzotik danslarla baştan çıkaran bir kadın karakter bulunmas gibi benzer unsurlarla tasvir edilse de eserin sonunda Wagner'in, Kundry adlı kadın karakter aracılığıyla, egzotizmi olumsuz bir kavram olarak ele aldığı görülmektedir. Operanın genelinde hoşa giden egzotik öğeler; egzotizmin örneği olarak gördüğümüz kadın karakterin, üçüncü perdede tövbe etmesi gereken ve kurtulmak istenilen bir karakter olarak yansıtılması sebebiyle, alışılagelmiş olan egzotizm algısı bambaşka bir yorum bulmuştur. 
Egzotizm, sıklıkla ele alınan bir konu olmamasına karşın, Romantik dönem bestecilerinin gerek benzer gerekse farklı yorumlamalarından da anlaşılabileceği üzere, eserlerde yarattığı etkiler sebebiyle, üzerinde düşünülmeye değer ve sadece "uzak diyarlara duyulan ilgi” ifadesiyle sınırlandırılamayacak kadar kapsamlı bir eğilimdir.

\footnotetext{
Hakem Değerlendirmesi: Dış bağımsız.

Çıkar Çatışması: Yazarlar çıkar çatışması bildirmemiştir.

Finansal Destek: Yazarlar bu çalışma için finansal destek almadığını beyan etmiştir.

Peer-review: Externally peer-reviewed.

Conflict of Interest: The authors have no conflict of interest to declare.

Grant Support: The authors declared that this study has received no financial support.
}

\section{Kaynakça/References}

Acunaz Eytemiz, Z. S. ve Güner Canbey, E. (2021). Robert Schumann Örneğinde Duygu Durum Bozukluklarının Yaratma Sürecine Yansımaları. Afyon Kocatepe Üniversitesi Akademik Müzik Araştırmaları Dergisi, 7(13), 94-107.

Babyak, T.B. (2014). Nietzsche, Debussy, and The Shadow of Wagner. (Ph. D. Thesis). Cornell University, New York.

Bellman, J. (1997). Introduction, The Exotic in Western Music. Boston: Northeastern University Press.

Bizet, G. (1905). Carmen: An opera in four acts [Musical score]. Edition Peters. (Original work published 1875).

Boran, İ. ve Şenürkmez, K.Y. (2015). Kültürel Tarih Işığında Çoksesli Batı Müziği. İstanbul: Yapı Kredi Kültür Sanat Yayıncilik.

Burnett, L., (2014). Savage Gardens, Original Sins: An Anarcho-Primitivist Reading of Wagner's Parsifal. Athens Journal of Humanities \& Arts, 1(4), 309-322.

Collisson, S., Chilingirian, L., O’Donovan, M., Hall, G., Hayes, M., Lankester, M., Lutchmayer, K., Mcgowan, K., Ogano, K., Rashbrook, S., Reitz, C. L., Rutherford- Johnson, T., Shirley, H. ve Derham, K. (2019). Klasik Müzik Kitabı (Tufan Göbekçin, Çev.). İstanbul: Alfa Yayınları.

Dahlhaus, C. (1971). Richard Wagners Musikdrame. New York: Cambridge University Press.

Emslie, B. (1991). Woman as Image and Narrative in Wagner's "Parsifal": A Case Study. Cambridge Opera Journal. 3(2), 109-124. New York: Cambridge University Press.

Fauser, A. (2005). Musical Encounters at the 1889 Paris World's Fair. New York, NY: University of Rochester Press.

Girgin, M. (2015). N. R. Korsakov “Şehrazad” senfonik süiti op. 35: Orkestra şefliği açısından teknik ve müzikal değerlendirme. (Yayımlanmamış Yüksek Lisans Tezi). Dokuz Eylül Üniversitesi Güzel Sanatlar Enstitüsü, İzmir

Griffiths, P. (2011). Batı Müziğinin Kısa Tarihi (M. Halim Spatar, Çev.). İstanbul: Türkiye İş Bankası Kültür Yayınları. Hentch, T. (1996). Hayali Doğu, Batı'nın Akdenizli Doğu'ya Politik Bakışı (Aysel Bora, Çev.). İstanbul: Metis Yayınları. Hopa, E. (2020). Rimski-Korsakov’un Şehrazat Senfonik Süiti’ndeki Fagot Sololarının İncelenmesi. Konservatoryum, 6(2), 105-116.

Köse, M. ve Küçük, M. (2015). Oryantalizm ve “Öteki” Algısı. Sosyal ve Kültürel Araştırmalar Dergisi, 1(1), $107-127$. Machlis, F. ve Forney, K. (2003). The Enjoyment of Music. New York: W.W. Norton \& Company. 
McClary, S. (1997). Structures of Identity and Difference in Bizet's Carmen, The Work of Opera: Genre, Nationhood, and Sexual Difference. New York: Columbia University Press,

Michels, U. ve Vogel, G. (2013). Müzik Atlası. İstanbul: Alfa Müzik.

Nazlı, A. (2011). Binbir Gece Masalları'nın Anadolu Türk masallarına etkileri üzerine bir araşttrma. (Yayımlanmamış Doktora Tezi). Selçuk Üniversitesi Sosyal Bilimler Enstitüsü, Konya

Schwarm, B. (2016, Nisan 8). Scheherazade. Encyclopedia Britannica. https://www.britannica.com/topic/Scheherazade-by-Rimsky-Korsakov

Thorpe, C., Yuill, C., Hobbs, M., Todd, M., Tomley ve S., Weeks, M. (2015). Sosyoloji Kitabı (Tufan Göbekçin, Çev.). İstanbul: Alfa Yayınları.

Yazar, İ. A. (2006). 18. ve 19. Yüzylllarda Opera Librettolarında Oryantalist Etkilerin Araşstırlması ve Karşılaştırllması. (Yüksek Lisans Tezi). İstanbul Üniversitesi Sosyal Bilimler Enstitüsü, İstanbul

Yener, F. (1992). 100 Opera. İstanbul: Bateş Yayınları. 